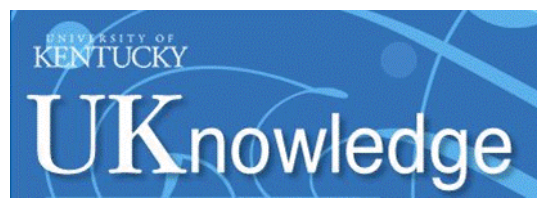

University of Kentucky

UKnowledge

\title{
A POPULATION-BASED ANALYSIS OF PATIENT AGE AND OTHER DISPARITIES IN THE TREATMENT OF OVARIAN CANCER IN CENTRAL APPALACHIA AND KENTUCKY
}

Robert Ore

University of Kentucky, robertore76@msn.com

Digital Object Identifier: https://doi.org/10.13023/etd.2019.170

Right click to open a feedback form in a new tab to let us know how this document benefits you.

\section{Recommended Citation}

Ore, Robert, "A POPULATION-BASED ANALYSIS OF PATIENT AGE AND OTHER DISPARITIES IN THE TREATMENT OF OVARIAN CANCER IN CENTRAL APPALACHIA AND KENTUCKY" (2019). Theses and Dissertations--Clinical Research Design. 4.

https://uknowledge.uky.edu/crd_etds/4

This Master's Thesis is brought to you for free and open access by the College of Public Health at UKnowledge. It has been accepted for inclusion in Theses and Dissertations--Clinical Research Design by an authorized administrator of UKnowledge. For more information, please contact UKnowledge@lsv.uky.edu. 


\section{STUDENT AGREEMENT:}

I represent that my thesis or dissertation and abstract are my original work. Proper attribution has been given to all outside sources. I understand that I am solely responsible for obtaining any needed copyright permissions. I have obtained needed written permission statement(s) from the owner(s) of each third-party copyrighted matter to be included in my work, allowing electronic distribution (if such use is not permitted by the fair use doctrine) which will be submitted to UKnowledge as Additional File.

I hereby grant to The University of Kentucky and its agents the irrevocable, non-exclusive, and royalty-free license to archive and make accessible my work in whole or in part in all forms of media, now or hereafter known. I agree that the document mentioned above may be made available immediately for worldwide access unless an embargo applies.

I retain all other ownership rights to the copyright of my work. I also retain the right to use in future works (such as articles or books) all or part of my work. I understand that I am free to register the copyright to my work.

\section{REVIEW, APPROVAL AND ACCEPTANCE}

The document mentioned above has been reviewed and accepted by the student's advisor, on behalf of the advisory committee, and by the Director of Graduate Studies (DGS), on behalf of the program; we verify that this is the final, approved version of the student's thesis including all changes required by the advisory committee. The undersigned agree to abide by the statements above.

Robert Ore, Student

Dr. David Mannino, Major Professor Dr. David Mannino, Director of Graduate Studies 


\title{
A POPULATION-BASED ANALYSIS OF PATIENT AGE AND OTHER DISPARITIES IN THE TREATMENT OF OVARIAN CANCER
} IN CENTRAL APPALACHIA AND KENTUCKY

\author{
THESIS \\ A thesis submitted in partial fulfillment of the \\ requirements for the degree of Master of Science in Clinical Research \\ Design in the College of Public Health \\ at the University of Kentucky
}

\author{
By \\ Robert Martin Ore \\ Lexington, Kentucky \\ Director: Dr. David Mannino, Professor of Medicine \\ Lexington, Kentucky \\ 2019
}

Copyright (C) Robert Ore, 2019 


\begin{abstract}
OF THESIS
A POPULATION-BASED ANALYSIS OF PATIENT AGE AND OTHER DISPARITIES IN THE TREATMENT OF OVARIAN CANCER IN CENTRAL APPALACHIA AND KENTUCKY
\end{abstract}

Objectives: Adherence to National Comprehensive Cancer Network (NCCN) guidelines for ovarian cancer treatment improves patient outcomes. The aim of this study is to assess disparities associated with ovarian cancer treatment in the state of Kentucky and Central Appalachia.

Methods: Patients diagnosed with ovarian cancer from 2007-2011 were extracted from administrative claims-linked Kentucky Cancer Registry data. NCCN compliance was defined by stage, grade, surgical procedure and chemotherapy. Selection criteria were carefully reviewed to ensure data quality and accuracy. Descriptive analysis, logistic regression, and Cox regression analyses were performed to examine factors associated with guidelines compliance and survival.

Results: Most women were age 65 years or older (62.5\%), had high grade (65.9\%) and advanced stage (61.0\%) ovarian cancer. Two-thirds of cases $(65.9 \%)$ received NCCN-recommended treatment for ovarian cancer. The hazard ratio (HR) of death for women who did not receive NCCN-compliant care was $62 \%$ higher compared to the women who did receive NCCN compliant treatment (HR 1.62, 95\% CI 1.11-2.35). Results from the logistic regression showed that NCCN-compliant treatment was more likely for: women age 65-74 years compared to age $20-49(\mathrm{OR}=3.32,95 \% \mathrm{CI}=1.32$ 8.32 ), late stage compared to early stage cancers (OR $0.32,95 \%$ CI $0.20-0.53$ ), receipt of care at tertiary hospitals $(\mathrm{OR}=1.92,95 \% \mathrm{CI}=1.10-3.34)$, and privately insured compared to Medicaid $(\mathrm{OR}=0.31,95 \% \mathrm{CI}=0.13-0.77)$ or Medicare $(\mathrm{OR}=0.31,95 \% \mathrm{CI}=0.15-0.66)$. 
Conclusions: When the treatment of ovarian cancer did not follow NCCNrecommendations, patients had a significantly higher risk of death. Women were less likely to receive NCCN-compliant care if they were of younger age (20-49 years), had early stage disease, were not privately insured, or had care provided at a non-tertiary hospital.

Keywords: NCCN Guideline Compliance, Ovarian Cancer, Healthcare disparities

$\underline{\text { Robert M Ore }}$

(Name of Student)

15DEC2018 
A POPULATION-BASED ANALYSIS OF PATIENT AGE AND OTHER DISPARITIES IN THE TREATMENT OF OVARIAN CANCER IN CENTRAL APPALACHIA AND KENTUCKY

\author{
By \\ Robert Martin Ore
}

David Mannino, MD

Director of Thesis

David Mannino, MD

Director of Graduate Studies

15DEC2018 


\title{
ACKNOWLEDGEMENTS
}

The additional contributors to this work are acknowledged in addition to the primary author, as listed below.

\footnotetext{
Robert M. Ore ${ }^{* 1}$, Quan Chen ${ }^{2}$, Christopher P. DeSimone ${ }^{1}$, Rachel W. Miller ${ }^{1}$, Lauren A. Baldwin ${ }^{1}$, John R. van Nagell, Jr. ${ }^{1}$, Bin Huang ${ }^{3}$, Thomas C. Tucker ${ }^{4}$, M. Symmes Johnson ${ }^{1}$, Tricia I. Fredericks ${ }^{1}$, and Frederick R. Ueland ${ }^{1}$.
}

\footnotetext{
${ }^{1}$ Division of Gynecologic Oncology, Department of Obstetrics and Gynecology, and Biostatistics Shared Resource Facility, Markey Cancer Center, Lexington KY.

${ }^{2}$ Biostatistics and Bioinformatics Shared Resource Facility, Markey Cancer Center, University of Kentucky, Lexington, KY

${ }^{3}$ Department of Biostatistics, College of Public Health, University of Kentucky, Lexington, KY

${ }^{4}$ Department of Epidemiology, College of Public Health, University of Kentucky, Lexington, KY
}

\author{
Robert M. Ore, MD ("Corresponding Author) \\ Division of Gynecologic Oncology \\ Department of Obstetrics and Gynecology \\ University of Kentucky, Markey Cancer Center, Lexington KY
}

Lexington, KY 40536

Email: robert.ore@uky.edu

859 257-2935 (office)

859 323-1602 (fax) 


\section{TABLE OF CONTENTS}

ACKNOWLEDGEMENTS $\quad$ iii

LIST OF TABLES $\quad$ v

LIST OF FIGURES Vi vi vi vis

CHAPTER 1. INTRODUCTION 1

CHAPTER 2. MATERIALS AND METHODS 3

CHAPTER 3. RESULTS 6

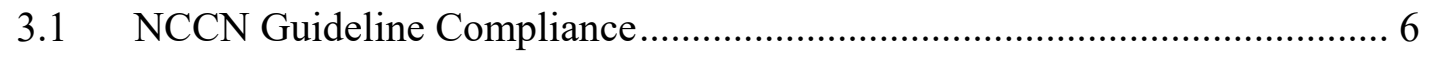

3.2 Patient Survival ................................................................................... 7

$\begin{array}{ll}\text { DISCUSSION } & 16\end{array}$

CONFLICT OF INTEREST STATEMENT 21

$\begin{array}{ll}\text { BIBLIOGRAPHY } & 22\end{array}$

$\begin{array}{ll}\text { VITA } & 26\end{array}$ 


\section{LIST OF TABLES}

Table 1. Characteristics of Patients with Ovarian Cancer by NCCN Guideline Adherence Status, 2007-2011 .............................................................. 8

Table 2. Factors Associated with Guideline Compliance based on the Logistic

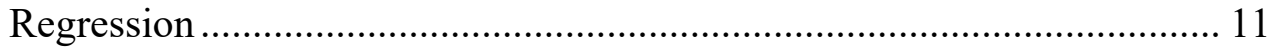

Table 3. Factors Associated with Survival from the Cox Regression Model.................. 13 


\section{LIST OF FIGURES}

Figure 1. Kaplan Meier Plots for Ovarian Cancer Patient Survival by Compliance

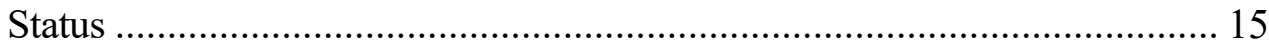




\section{HIGHLIGHTS}

- There is a higher risk of death if ovarian cancer treatment is not NCCN-compliant

- Younger women are more likely to receive non-compliant care than older women

- Non-compliance was also more common for early stage disease and non-private insurance 


\section{CHAPTER 1. INTRODUCTION}

Ovarian cancer is one of the more lethal gynecologic cancers as it regularly presents in advanced stage (1) and many women do not receive expert-recommended care (2). Until progress is made with the early detection of ovarian cancer, it is important to understand the barriers preventing women from receiving NCCN-compliant treatment. The National Comprehensive Cancer Network (NCCN) publishes detailed guidelines for the treatment of ovarian cancer which include comprehensive surgical staging for early stage cancers and aggressive surgical cytoreduction for advanced stage disease. With the exception of low grade early stage ovarian malignancies, platinum and taxane-based chemotherapy is recommended following surgery. Adherence to NCCN guidelines has been shown to improve patient outcomes (2). Unfortunately, as many as two-thirds of women with ovarian cancer are not referred to a gynecologic oncologist for their primary surgery (3) (4) and a similar fraction do not receive NCCN-compliant care (2).

A number of factors have previously been associated with non-compliant treatment according to NCCN guidelines. These include hospital and surgeon case volume (2), treatment at NCI Comprehensive Cancer Center facilities (5), cancer stage (6), geographic proximity to the hospital (7), race (8), and socioeconomic status (8). Even though the median age at diagnosis for ovarian cancer is 63 years, $55 \%$ of women diagnosed with invasive ovarian cancer are younger than 65 years of age (9); therefore, women of all ages should be included in population-based evaluations. We should also consider whether non-compliant treatment is an intentional act of commission. A single institutional report from the University of Alabama at Birmingham noted that common reasons for non-compliance were intentional and related to: chemotherapy toxicity, 
disease progression, patient refusal, and co-morbidities preventing recommended surgery or chemotherapy (10). An analysis of guideline concordance for colorectal cancer in the Appalachian region of Kentucky demonstrated that non-compliance was associated with chronic medical conditions, including myocardial infarction and congestive heart failure; and surgical non-compliance was associated with low volume centers and hospitals that were not designated by the Commission on Cancer (COC) (11).

Our study objective was to perform a detailed analysis of treatment disparities for ovarian cancer in the state of Kentucky and Central Appalachia based on published NCCN guidelines. 


\section{CHAPTER 2. MATERIALS AND METHODS}

This is a retrospective, population-based investigation of women diagnosed with ovarian cancer while living in the state of Kentucky from January 1, 2007 to December 31, 2011. Permission to perform the investigation was granted by the University of Kentucky Institutional Review Board as an exempt protocol.

Ovary cancer cases were selected based on ICD-O-3 site codes C569, and extracted from the Kentucky Cancer Registry (KCR) database. The KCR database was linked to insurance claim databases in the state of Kentucky including Medicare, Medicaid, and private insurers. This unique merging of clinical data eliminated patient age constraints seen when cancer registries are coupled to Medicare (patients age 65 years and older). In addition, use of both private and non-private insurers allow for a more complete review of medical comorbidities and insurance-related variables.

Patient eligibility included an ovarian cancer diagnosis in the state of Kentucky, age over 20 years, and a first diagnosis of an invasive cancer. To ensure complete and accurate treatment information, we included only patients with continuous insurance enrollment in the first year of cancer diagnosis (month of cancer diagnosis and 12 months following) or till the month of death in the first year. Borderline and non-epithelial ovarian malignancies were excluded from this study. There were 1,450 cases identified with a diagnosis of ovarian cancer during the study period. Three hundred and sixty-one cases were excluded, as they had insufficient details to determine surgical procedures performed. Twenty were excluded due to age under 20 years, and 179 were excluded as ovarian cancer was not their first cancer diagnosis. An additional 68 cases were excluded due to non-epithelial histology. Since we defined NCCN-compliance to include 
chemotherapy information captured from KCR linked claims files, 322 cases were excluded as they did not have at least 13 months of continuous claims data. Thus, there were a total of 413 cases for the complete analysis.

The primary outcome investigated was compliance with NCCN recommendations for ovarian cancer treatment. Chemotherapy and surgical guideline compliance were grouped together to form a single bivariate value for compliance. For stages IIIB and below, adherence required a minimum performance of oophorectomy and lymphadenectomy, whereas stages IIIC and above required a minimum of oophorectomy and omentectomy, and allowed for more extensive cytoreductive procedures. Guideline compliance required chemotherapy administration for all study cases with the exception of stage IA and stage IB grade 1 cancers. Surgical information was captured using KCR data, and chemotherapy information was identified by claims data linked to KCR data.

Hospitals were classified as high volume ( $>15$ cases per year) or low volume $(<15$ cases per year) based on the number of ovarian cancer cases performed. Academic hospitals were defined to be tertiary hospitals. The patient-specific variables analyzed were: age, race, insurance type, Appalachian residence versus metropolitan status, educational level (percentage with high school education at county level), income level (percentage below the poverty level at county level), insurance type, treatment with neoadjuvant chemotherapy, and geographical distance to the closest tertiary hospital. We used the Great Circle Distance (GCD) method to calculate geographical distance, adapted North American Association of Central Cancer Registries (NAACCR)'s SAS application (GIS Resources. NAACCR https://www.naaccr.org/gis-resources/\#GREATCIRCLE). Appalachian status was based on the definition from the Appalachia Regional 
Commission (https://www.arc.gov/index.asp). The 2003 Rural-Urban Continuum Codes were used to define metro and non-metro status with values 1-3 as metro and 4-9 as nonmetro https://www.ers.usda.gov/data-products/rural-urban-continuum-codes/. The Charlson Comorbidity Index (CCI) was assigned based on KCR linked claims data from a time period spanning 12 months to one month prior to cancer diagnosis. The CCI variable was treated as unknown when 12 months of continuous claims coverage prior to the cancer diagnosis was unobtainable. Tumor-related variables included: cell type, stage, grade, number of lymph nodes examined, and tumor size.

Descriptive analysis was conducted for all variables. Bivariate analyses with ChiSquare tests were performed to examine the association between guideline compliance and other covariates. Multivariate logistic regression models were fitted to determine significant factors associated with the delivery of NCCN-compliant care. Kaplan-Meier plots and Log-Rank tests were conducted for survival analysis. A Cox regression analysis was performed to determine the survival effects of various covariates, including NCCN compliance. All analyses were done using SAS Statistical software version 9.4 (SAS Institute, Inc., Cary, NC). Statistical tests were two-sided with a $p$-value $\leq 0.05$ used to identify statistical significance. 


\section{CHAPTER 3. RESULTS}

Two hundred and seventy-two women out of a total study population of 413 $(65.9 \%)$ received NCCN guideline compliant care. For the 141 women who did not receive guideline-compliant care, 87 (61.7\%) did not receive the recommended chemotherapy, and $79(56.0 \%)$ did not receive the appropriate surgery.

The summary of demographic characteristics is shown in Table 1 . The mean age of the study population was 65.5 years, and $62.3 \%$ of study subjects were 65 years or older. More than half of the cancers were diagnosed at an advanced stage $(60.9 \%)$. The majority were also grade 3 or 4 malignancies (65.7\%). Fewer than $10 \%$ of patients had a Charlson Comorbidity Index greater than 2 . Only $39.1 \%$ of cases were treated at a tertiary hospital, while $58 \%$ were treated at high volume hospitals as defined by at least 15 ovarian cancer cases per year. Medicare insured $65 \%$ of the women in this study. Although more women were treated in non-Appalachian metropolitan areas $(44.7 \%)$ than any other, $31.2 \%$ were still treated in rural Appalachia.

\subsection{NCCN Guideline Compliance}

The bivariate analysis between patient characteristics and NCCN-compliance are listed in Table 1. Women who received NCCN-adherent care were more likely to have late stage disease (stage III and stage IV), smaller size tumors (less than $10 \mathrm{~cm}$ ), and treatment at a tertiary hospital. Women from non-Appalachian metropolitan areas were more likely $(51.9 \%)$ to have private insurance carriers, whereas women from Appalachian rural areas were more likely to be covered by Medicaid. Patient income and education level were not associated with NCCN compliance or survival. The average 
Great Circle Distance (GCD) to the closest academic hospital for all subjects was 62.9 miles ( \pm 48.5 miles). The average GCD for non-compliant cases GCD was 59.8 miles ( \pm 45.3 miles) compared to NCCN-compliant cases of 64.5 miles ( \pm 50.1 miles). There was no statistical difference between these groups.

The characteristics associated with NCCN guideline adherence on multivariate logistic regression are shown in Table 2 . Women of age 65-74 years were significantly more likely to be guideline compliant compared to women age 20-49 years (OR 3.316, 95\% CI 1.322-8.320). Compared to stage IIIC and IV, treatment of earlier stage disease was less NCCN-compliant (OR $0.32,95 \% \mathrm{CI} 0.198-0.526)$. Patients treated at a tertiary hospital were also more likely to receive NCCN-adherent care (OR 1.921, 95\%CI 1.1043.341). Compared to women who were privately insured, those insured by Medicaid (OR $0.311,95 \%$ CI $0.125-0.774$ ) or Medicare (OR $0.312,95 \%$ CI $0.148-0.659$ ) were much less likely to be guideline compliant.

\subsection{Patient Survival}

The results from the Cox regression model are shown in Table 3. NCCN guideline compliant treatment was associated with significantly better survival $(\mathrm{HR}=1.615,95 \% \mathrm{CI}$ 1.111-2.347) than non-compliant cases. In addition, women who lived in non-Appalachian metropolitan areas had better survival compared to women living in rural Appalachian areas (HR $0.698,95 \%$ CI $0.491-0.990)$. Patient's distance to closest tertiary hospital was marginally associated with survival (HR 1.003, 95\%CI 1.000-1.006). As expected, overall survival was better for younger compared to older women, early compared to late stage diagnosis, and women with low compared to high CCI. 
Table 1. Characteristics of Patients with Ovarian Cancer by NCCN Guideline Adherence Status, 2007-2011

\begin{tabular}{|c|c|c|c|c|c|c|c|}
\hline \multirow[t]{2}{*}{ Variables } & \multicolumn{2}{|c|}{ Total } & \multicolumn{2}{|c|}{$\begin{array}{c}\text { Guideline } \\
\text { Non-Compliant }\end{array}$} & \multicolumn{2}{|c|}{$\begin{array}{l}\text { Guideline } \\
\text { Compliant }\end{array}$} & \multirow[t]{2}{*}{ P value } \\
\hline & $\mathbf{N}$ & $\%$ & $\mathbf{N}$ & $\%$ & $\mathbf{N}$ & $\%$ & \\
\hline Total & 413 & 100.0 & 141 & 34.1 & 272 & 65.7 & \\
\hline \multicolumn{8}{|c|}{ Age } \\
\hline $20-49$ & 46 & 11.1 & 20 & 43.5 & 26 & 56.5 & 0.121 \\
\hline $50-64$ & 109 & 26.3 & 34 & 31.2 & 75 & 68.8 & \\
\hline $65-74$ & 163 & 39.4 & 48 & 29.5 & 115 & 70.6 & \\
\hline$>75$ & 95 & 22.9 & 39 & 41.1 & 56 & 59.0 & \\
\hline \multicolumn{8}{|c|}{ Race } \\
\hline $\begin{array}{l}\text { White and } \\
\text { other }\end{array}$ & 402 & 97.1 & 138 & 34.3 & 264 & 65.7 & 0.756 \\
\hline Black & 11 & 2.7 & 3 & 27.3 & 8 & 72.7 & \\
\hline \multicolumn{8}{|c|}{ Stage } \\
\hline I & 114 & 27.5 & 47 & 41.2 & 67 & 58.8 & 0.000 \\
\hline II & 47 & 11.4 & 23 & 48.9 & 24 & 51.1 & \\
\hline III & 166 & 40.1 & 37 & 22.3 & 129 & 77.7 & \\
\hline IV & 86 & 20.8 & 34 & 39.5 & 52 & 60.5 & \\
\hline \multicolumn{8}{|c|}{ Grade } \\
\hline 1 & 23 & 5.6 & 9 & 39.1 & 14 & 60.9 & 0.097 \\
\hline 2 & 64 & 15.5 & 26 & 40.6 & 38 & 59.4 & \\
\hline 3 & 165 & 39.9 & 52 & 31.5 & 113 & 68.5 & \\
\hline 4 & 107 & 25.8 & 29 & 27.1 & 78 & 72.9 & \\
\hline Unknown & 54 & 13.0 & 25 & 46.3 & 29 & 53.7 & \\
\hline \multicolumn{8}{|c|}{ Tumor Size } \\
\hline$<5 \mathrm{~cm}$ & 78 & 18.8 & 23 & 29.5 & 55 & 70.5 & 0.030 \\
\hline $5-10 \mathrm{~cm}$ & 100 & 24.2 & 24 & 24.0 & 76 & 76.0 & \\
\hline$>10 \mathrm{~cm}$ & 148 & 35.7 & 60 & 40.5 & 88 & 59.5 & \\
\hline Unknown & 87 & 21.0 & 34 & 39.1 & 53 & 60.9 & \\
\hline
\end{tabular}


Table 1. (continued)

\begin{tabular}{|c|c|c|c|c|c|c|c|}
\hline \multicolumn{8}{|c|}{ Charlson Comorbidity Index } \\
\hline 0 & 226 & 54.6 & 71 & 31.4 & 155 & 68.6 & \multirow{5}{*}{0.216} \\
\hline 1 & 100 & 24.2 & 34 & 34.0 & 66 & 66.0 & \\
\hline 2 & 20 & 4.8 & 9 & 45.0 & 11 & 55.0 & \\
\hline 3 or greater & 11 & 2.7 & 2 & 18.2 & 9 & 81.8 & \\
\hline Unknown & 56 & 13.5 & 25 & 44.6 & 31 & 55.4 & \\
\hline \multicolumn{8}{|c|}{ Tertiary versus Non Tertiary Hospital } \\
\hline $\begin{array}{l}\text { Tertiary } \\
\text { Hospital }\end{array}$ & 162 & 39.1 & 46 & 28.4 & 116 & 71.6 & \multirow{2}{*}{0.048} \\
\hline $\begin{array}{l}\text { Non Tertiary } \\
\text { Hospital }\end{array}$ & 251 & 60.6 & 95 & 37.9 & 156 & 62.2 & \\
\hline \multicolumn{8}{|c|}{ Hospital Volume of Ovary Cancer Cases per year } \\
\hline $\begin{array}{l}>15 \\
\text { cases/year }\end{array}$ & 240 & $\mathbf{5 8 . 0}$ & 74 & 30.8 & 166 & 69.2 & \multirow[t]{2}{*}{0.095} \\
\hline$<15$ cases/year & 173 & 41.8 & 67 & 38.7 & 106 & 61.3 & \\
\hline \multicolumn{8}{|c|}{ Income Level } \\
\hline Low & 114 & 27.5 & 39 & 34.2 & 75 & 65.8 & \multirow{4}{*}{0.873} \\
\hline Moderate & 103 & 24.9 & 33 & 32.0 & 70 & 68.0 & \\
\hline High & 94 & 22.7 & 31 & 33.0 & 63 & 67.0 & \\
\hline Very High & 102 & 24.6 & 38 & 37.3 & 64 & 62.8 & \\
\hline \multicolumn{8}{|c|}{ Insurance Type } \\
\hline Not Insured & 3 & 0.7 & 2 & 66.7 & 1 & 33.3 & \multirow{5}{*}{0.068} \\
\hline $\begin{array}{l}\text { Private } \\
\text { Insurance }\end{array}$ & 106 & 25.6 & 26 & 24.5 & 80 & 75.5 & \\
\hline Medicaid & 33 & 8.0 & 16 & 48.5 & 17 & 51.5 & \\
\hline Medicare & 269 & 65.0 & 97 & 36.1 & 172 & 63.9 & \\
\hline Other Public & 1 & 0.2 & 0 & 0.0 & 1 & 100.0 & \\
\hline Unknown & 1 & 0.2 & 0 & 0.0 & 1 & 100.0 & \\
\hline
\end{tabular}


Table 1. (continued)

\begin{tabular}{|c|c|c|c|c|c|c|c|}
\hline \multicolumn{8}{|c|}{ Appalachian Residence Metropolitan Status } \\
\hline $\begin{array}{l}\text { Appalachian } \\
\text { Metro Area }\end{array}$ & 18 & 4.3 & 2 & 11.1 & 16 & 88.9 & \\
\hline $\begin{array}{l}\text { Appalachian } \\
\text { Rural Area }\end{array}$ & 129 & 31.2 & 46 & 35.7 & 83 & 64.3 & \\
\hline $\begin{array}{l}\text { Non } \\
\text { Appalachian } \\
\text { Metro Area }\end{array}$ & 185 & 44.7 & 62 & 33.5 & 123 & 66.5 & 0.170 \\
\hline $\begin{array}{l}\text { Non } \\
\text { Appalachian } \\
\text { Rural Area }\end{array}$ & 81 & 19.6 & 31 & 38.3 & 50 & 61.7 & \\
\hline \multicolumn{8}{|c|}{ Chemotherapy Adherence } \\
\hline $\begin{array}{l}\text { Chemothera } \\
\text { py Adherent }\end{array}$ & 323 & 78.2 & 54 & 16.7 & 269 & 83.3 & \\
\hline $\begin{array}{l}\text { Chemothera } \\
\text { py Non } \\
\text { Adherent }\end{array}$ & 90 & 21.8 & 87 & 96.7 & 3 & 3.3 & $<0.001$ \\
\hline \multicolumn{8}{|c|}{ Surgery Adherence } \\
\hline $\begin{array}{l}\text { Surgery } \\
\text { Adherence }\end{array}$ & 334 & 80.9 & 62 & 18.6 & 272 & 81.4 & \\
\hline $\begin{array}{l}\text { Surgery Non } \\
\text { Adherence }\end{array}$ & 79 & 19.1 & 79 & 100.0 & 0 & 0.0 & \\
\hline
\end{tabular}


Table 2. Factors Associated with Guideline Compliance based on the Logistic Regression

\begin{tabular}{|c|c|c|c|c|}
\hline Variable & OR* & \multicolumn{2}{|c|}{ 95\% C.I. } & P-value \\
\hline \multicolumn{5}{|c|}{ Age Groups } \\
\hline $50-64$ & 1.897 & 0.851 & 4.228 & \multirow[t]{4}{*}{0.027} \\
\hline $65-74$ & 3.316 & 1.322 & 8.320 & \\
\hline$>75$ & 1.730 & 0.661 & 4.528 & \\
\hline \multirow{2}{*}{\multicolumn{5}{|c|}{ Stage }} \\
\hline & & & & \\
\hline Stage IA IB with Grade 1 & 0.151 & 0.022 & 1.020 & \multirow[t]{3}{*}{$<0.001$} \\
\hline Stage IA-IIIB & 0.323 & 0.198 & 0.526 & \\
\hline Stage IIIC-IV & Ref & & & \\
\hline \multicolumn{5}{|c|}{ Grade } \\
\hline Grade 2 & 0.421 & 0.093 & 1.898 & \multirow[t]{5}{*}{0.071} \\
\hline Grade 3 & 0.548 & 0.128 & 2.351 & \\
\hline Grade 4 & 0.529 & 0.119 & 2.358 & \\
\hline Unknown & 0.212 & 0.045 & 0.990 & \\
\hline Grade1 & Ref & & & \\
\hline \multicolumn{5}{|c|}{ Charlson Comorbidity Index } \\
\hline 1 & 1.188 & 0.675 & 2.090 & \multirow[t]{5}{*}{0.171} \\
\hline 2 & 0.731 & 0.267 & 1.999 & \\
\hline $3+$ & 3.803 & 0.710 & 20.356 & \\
\hline Unknown & 0.544 & 0.263 & 1.128 & \\
\hline 0 & Ref & & & \\
\hline \multicolumn{5}{|c|}{ Tertiary } \\
\hline Tertiary Hospital & 1.921 & 1.104 & 3.341 & \multirow[t]{2}{*}{0.021} \\
\hline Non Tertiary Hospital & Ref & & & \\
\hline
\end{tabular}


Table 2. (continued)

\begin{tabular}{|c|c|c|c|c|}
\hline \multicolumn{5}{|c|}{ Income Level } \\
\hline Low & 1.014 & 0.362 & 2.834 & \multirow{4}{*}{0.956} \\
\hline Moderate & 1.000 & 0.339 & 2.955 & \\
\hline High & 1.188 & 0.539 & 2.615 & \\
\hline Very High & Ref & & & \\
\hline \multicolumn{5}{|c|}{ Insurance Status } \\
\hline Medicaid & 0.311 & 0.125 & 0.774 & \\
\hline Medicare & 0.312 & 0.148 & 0.659 & 0.003 \\
\hline Private Insured & Ref & & & \\
\hline \multicolumn{5}{|c|}{ Appalachian Residence and Metropolitan Status } \\
\hline Appalachian Metro Area & 5.069 & 0.890 & 28.876 & \\
\hline Non Appalachian Metro Area & 1.325 & 0.480 & 3.662 & 0.166 \\
\hline Non Appalachian Rural Area & 0.847 & 0.356 & 2.016 & \\
\hline Appalachian Rural Area & Ref & & & \\
\hline *OR, Odds Ratio & & & & \\
\hline
\end{tabular}


Table 3. Factors Associated with Survival from the Cox Regression Model

\begin{tabular}{|c|c|c|c|c|}
\hline Variable & \multicolumn{3}{|c|}{ 95\% C.I. } & P-value \\
\hline \multicolumn{5}{|c|}{ Age Groups } \\
\hline $50-64$ & 1.732 & 1.028 & 2.919 & \multirow[t]{4}{*}{0.043} \\
\hline $65-74$ & 1.732 & 0.974 & 3.082 & \\
\hline$>75$ & 2.316 & 1.256 & 4.271 & \\
\hline \multirow{2}{*}{\multicolumn{5}{|c|}{$20-49$}} \\
\hline & & & & \\
\hline Stage I & 0.090 & 0.054 & 0.151 & \multirow[t]{4}{*}{$<0.001$} \\
\hline Stage II & 0.185 & 0.108 & 0.315 & \\
\hline Stage III & 0.653 & 0.480 & 0.888 & \\
\hline Stage IV & Ref & & & \\
\hline \multicolumn{5}{|c|}{ Grade } \\
\hline Grade & & & & \multirow[t]{6}{*}{0.325} \\
\hline Grade 2 & 1.114 & 0.477 & 2.604 & \\
\hline Grade 3 & 1.329 & 0.599 & 2.946 & \\
\hline Grade 4 & 1.251 & 0.553 & 2.830 & \\
\hline Unknown & 0.831 & 0.341 & 2.026 & \\
\hline Grade1 & Ref & & & \\
\hline \multicolumn{5}{|c|}{ Charlson Comorbidity Index } \\
\hline 1 & 1.101 & 0.794 & 1.528 & \multirow[t]{5}{*}{0.323} \\
\hline 2 & 1.575 & 0.868 & 2.859 & \\
\hline $3+$ & 2.458 & 1.200 & 5.033 & \\
\hline Unknown & 1.506 & 0.970 & 2.339 & \\
\hline 0 & Ref & & & \\
\hline \multicolumn{5}{|c|}{ Tertiary } \\
\hline Tertiary Hospital & 1.034 & 0.765 & 1.397 & \multirow[t]{2}{*}{0.830} \\
\hline Non Tertiary Hospital & Ref & & & \\
\hline
\end{tabular}


Table 3. (continued)

\begin{tabular}{|c|c|c|c|c|}
\hline \multicolumn{5}{|c|}{ Insurance Status } \\
\hline Medicaid & 1.340 & 0.773 & 2.323 & \multirow{3}{*}{0.510} \\
\hline Medicare & 1.188 & 0.780 & 1.809 & \\
\hline \multirow{2}{*}{\multicolumn{5}{|c|}{$\begin{array}{c}\text { Ref } \\
\text { Appalachian Residence and Metropolitan Status }\end{array}$}} \\
\hline & & & & \\
\hline Appalachian Metro Area & 0.876 & 0.440 & 1.742 & \multirow{4}{*}{0.194} \\
\hline Non Appalachian Metro Area & 0.698 & 0.491 & 0.990 & \\
\hline Non Appalachian Rural Area & 0.742 & 0.497 & 1.108 & \\
\hline Appalachian Rural Area & Ref & & & \\
\hline GCD to Closest Tertiary Hospital & 1.003 & 1.000 & 1.006 & 0.094 \\
\hline \multicolumn{5}{|c|}{ Guideline Adherence } \\
\hline NCCN Guideline Non Adherent & 1.615 & 1.111 & 2.347 & \multirow{2}{*}{0.012} \\
\hline NCCN Guideline Adherent & Ref & & & \\
\hline *HR, Hazard Ratio & & & & \\
\hline
\end{tabular}




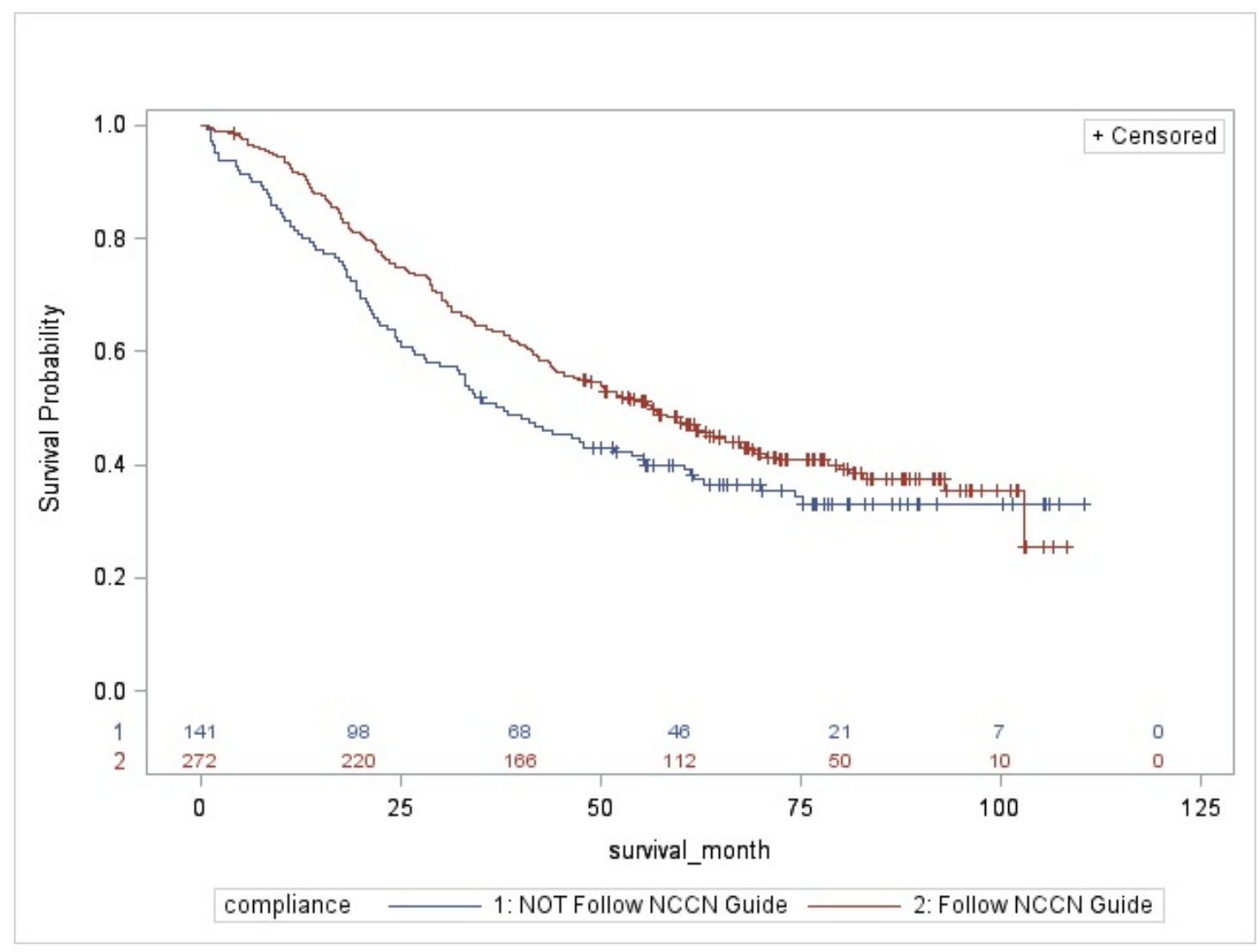

Figure 1. Kaplan Meier Plots for Ovarian Cancer Patient Survival by Compliance Status 


\section{DISCUSSION}

Ovarian cancer remains a significant cause of cancer death for women. One way to improve cancer outcomes is to ensure that women have access to expert-recommended care. Cancer incidence rates in Kentucky are among the highest in the United States, and the geographical region of Central Appalachia has numerous barriers that may limit access to expert medical care. Understanding the specific disparities is critical to improving ovarian cancer outcomes in this region.

The age adjusted incidence for ovarian cancer in the state of Kentucky in 20132014 was 10 cases per 100,000 people, similar to the national rate of 11.9 cases per 100,000 people (12). The corresponding age-adjusted mortality rate is 6.8 per 100,000 in Kentucky versus 7.2 per 100,000 nationwide (12). Compliance rates for NCCNrecommended treatment for ovarian cancer have not been previously reported for the state of Kentucky or Central Appalachia.

In this investigation, the overall NCCN compliance rate for the treatment of ovarian cancer was $65 \%$. As reported in other studies, women who received guidelinecompliant care had better overall survival. In our multivariate analysis, younger women (20-49 years) were significantly less likely to receive guideline recommended ovarian cancer treatment compared to age 65-74 years. Previous publications have reported that older women are at risk of receiving NCCN non-compliant care for ovarian cancer (7) (13) (14) (8), but our findings are the first show this disparity in younger women. This is particularly poignant when considering the potential number of life-years at risk for young women diagnosed with cancer. When using Medicare-linked databases, 
population-based reports are restricted to age 65 years or older (8). In our investigation, we were able to include all women age 20 years or older.

We elected to analyze age as a categorical as opposed to a continuous variable. This is logical as expert organization guidelines directing management of adnexal masses vary for premenopausal versus postmenopausal women (15). Furthermore, age related comorbidities are likely to be a greater factor in elderly women, as opposed to those who have just gone through menopause. Consequently, utilizing three age strata $(20-49,65-$ $74,>75)$ considers age in relation to these key factors, as opposed to consideration of age as a continuous variable. The results of our survival analysis demonstrate that younger age is associated with better survival; which is an expected result. The results of our logistic regression, demonstrate that younger age is associated with inferior guideline compliance, which is unexpected. This may suggest that decision-making guidelines in the younger than 50 years age group are not satisfactory.

Other publications have demonstrated low rates of NCCN guideline compliance for early stage cancers (6) (13). We also find that women with early stage ovarian cancer are less likely to receive NCCN-compliant care. As young women are more likely to have early stage disease (16), it is possible that stage and age are confounding factors in these analyses. Patients with early stage ovarian cancer are more likely to have appropriate staging and treatment when their initial surgery is performed by a gynecologic oncologist (17), so referral to a specialist is an important consideration.

In our study, patients with private insurance were more likely to receive guideline-compliant treatment than those with Medicaid or Medicare. This relationship between insurance provider and quality of care in ovarian cancer has been previously 
reported (14). It is not well understood why the type of insurance impacts the quality of treatment, though possible explanations include differences in physician reimbursement, cultural issues relating to access, or the possibility that insurance type may be a surrogate variable for socioeconomic status. It is important to note that in this investigation, patient education and income status were not associated with differences in NCCN-compliance or with overall survival.

NCCN guideline compliance was higher when treatment was provided at a tertiary care facility. It is well known that for the treatment of ovarian cancer, high volume hospitals, and experienced surgeons provide more guideline-concordant care (2). In addition, a recent report demonstrated greater rates of concordance when care was provided at NCI-designated Comprehensive Cancer Centers (CCC), compared to both high and low volume hospitals that were not NCI-designated CCC hospitals (5).

Other publications on ovarian cancer treatment have commented on disparities in guideline concordance based on socioeconomic status and race (18). No race disparate care was noted in our analysis, but the evaluation is limited by small numbers of African Americans in Central Appalachia (1.9\%) and the state of Kentucky (7.9\%). Insurance type may have served as a surrogate variable for socioeconomic status, as income levels are based upon census tract data in relationship to a subject's zip code of residence, while Medicaid insurance status is linked to low income on an individual level. We did observe a survival difference favoring non-Appalachian metropolitan populations compared to rural Appalachian populations. It is not evident whether this is related to the quality of care or other factors. Increased cancer mortality for Appalachian populations is a 
relationship previously accredited to several factors including, medical comorbidities and access to care (19).

The literature is replete with guidelines and strategies for the preoperative evaluation of an ovarian mass; nevertheless, disparate cancer treatment remains commonplace. Many women are still not referred to a gynecologic oncologist for their initial ovarian cancer operation (17) (3). Ultrasound is available worldwide as a reliable and objective method to evaluate ovarian tumors (20) (21). Serial sonography further enhances ultrasound's ability to differentiate benign from malignant ovarian tumors (22) (23). In addition, multivariate index assays are highly sensitive in detecting malignancy (24) (25) (26) (27) including early stage cancers (28), and can be combined with ultrasound to further stratify the likelihood of malignancy (29). These practical preoperative evaluation strategies should be considered for all women whose ovarian tumors are concerning enough to require surgery, regardless of cancer stage, patient age, location, or insurance provider.

The authors acknowledge several study limitations. Claims data allowed us to determine whether or not chemotherapy was received, but we were unable to determine individual agents or number of cycles. We were also unable to determine the subspecialty or case volume of the primary surgeon, both of which have been associated with survival in other studies (14) (2). Lastly, our survival analysis did not include parameters related to the extent of primary cytoreduction, or parameters related to disease recurrence, including time to recurrence, and specific chemotherapy agents administered.

Our study has the following strengths. Our team linked KCR data to the majority of insurance databases our state, thereby minimizing insurance provider related biases. 
Such biases are potentially significant in regards to age (Medicare - age over 65), and in regards to socioeconomic status (public versus private insurance in relation to patient income level). Our study gave a thorough account of medical comorbidities, a significant confounding variable that impacts decisions related to surgery and chemotherapy. The requirement for 13 months of continuous claims data mandated the exclusion of a substantial number of cases, but enabled us to capitalize on features of our KCRinsurance provider linked database. Lastly, we were able to use this comprehensive database to investigate patterns of care for ovarian cancer in Central Appalachia, an underserved and understudied region of the United States.

The findings of this investigation reaffirm that ovarian cancer survival is highest when treatment is concordant with published NCCN guidelines. Women with early stage disease, non-private insurance, or treatment at non-tertiary care hospitals are more likely to receive non-compliant care. We also report that younger women with ovarian cancer are significantly less likely to receive NCCN compliant care. Continued patient and physician education is needed to ensure that available imaging and biomarker tests are routinely used to help identify high risk women for referral to an ovarian cancer specialist, regardless of cancer stage, location, insurance provider, or patient age. 


\section{CONFLICT OF INTEREST STATEMENT}

The authors have no conflicts of interest to report. Dr. Bin Huang received the grant funding support (NIH (NCI) P30 CA177558) through the University of Kentucky Markey Cancer Center during the conduct of this study. 


\section{BIBLIOGRAPHY}

1. Trends in Surgery and Chemotherapy for Women Diagnosed with Ovarian Cancer in the

United States. Linda C. Harlan, Limin X. Clegg, Edward L. Trimble. 2003, Journal of Clinical Oncology, pp. 3488-3494.

2. Adherence to Treatment Guidelines for Ovarian Cancer as a Measure of Quality Care.

Bristow, Robert E., et al., et al. 2013, Obstetrics and Gynecology, pp. 1226-1234.

3. Effect of surgeon specialty on processes of care and outcomes for ovarian cancer patients.

Earle, CC, et al., et al. Feb 2006, Journal of the National Cancer Institute, pp. 172-80.

4. A population-based study of patterns of care for ovarian cancer: who is seen by a gynecologic oncologist and who is not? Carney, ME, et al., et al. Jan 2002, Gynecologic Oncology, pp. 36-42.

5. Impact of National Cancer Institute Comprehensive Cancer Centers on Ovarian Cancer Treatment and Survival. Bristow, Robert E., et al., et al. 2015, J Am Coll Surg, pp. 940950.

6. Socioeconomic status as a predictor of adherence to treatment guidelines for early-stage ovarian cancer. Hodeib, Melissa, et al., et al. 2015, Gynecologic Oncology, pp. 121127.

7. Spatial analysis of adherence to treatment guidelines for advanced-stage ovarian cancer and the impact of race and socioeconomic status. Bristow, Robert E., et al., et al. 2014, Gynecologic Oncology, pp. 60-67.

8. Sociodemographic Disparities in Advanced Ovarian Cancer Survival and Adherence to Treatment Guidelines. Bristow, Robert E., et al., et al. 2015, Obstetrics and Gynecology, pp. 833-842.

9. National Cancer Institute, Surveillance Epidemiology and End Results Program. [Online] [Cited: 5 April 2017.] https://seer.cancer.gov/statfacts/html/ovary.html.

10. Reasons for failure to deliver National Comprehensive Cancer Network (NCCN) - adherent care in the treatment of epithelial ovarian cancer at an NCCN cancer center. Erickson, Britt K., et al., et al. 2014, Gynecologic Oncology, pp. 142-146.

11. Clinica, Sociodemographic, and Service Provider Determinants of Guideline Concordant Colorectal Cancer Care for Appalachian Residents. Fleming, Steven T, et al., et al. 2013, The Journal of Rural Health, pp. 27-39.

12. Kentucky Cancer Registry. The population-based central cancer registry for the Commonwealth of Kentucky. [Online] [Cited: 28 Febrary 2017.] https://www.kcr.uky.edu/.

13. Ovarian Cancer: Patterns of surgical care across the United States. Goff, Barbara A., et al., et al. 2006, Gynecologic Oncology, pp. 383-390. 
14. Trends in Surgery and Chemotherapy for Women Diagnosed with Ovarian Cancer in the United States. Harlan, Linda C., Clegg, Limin X. and Trimble, Edward L. 2003, Journal of Clinical Oncology, pp. 3488-3494.

15. ACOG Practice Bulletin. Management of adnexal masses. American College of

Obstetricians and Gynecologists. Jul 2007 , Obstetrics and Gynecology, pp. 201-14.

16. Ovarian cancer in younger vs older women: a population-based analysis. Chan, JK, et al., et al. Nov 2006, British Journal of Cancer, pp. 1314-20.

17. Who should operate on patients with ovarian cancer? An evidence-based review. Giede, KC, et al., et al. Nov 2005, Gynecologic Oncology, pp. 447-61.

18. The effect of neighborhood-level socioeconomic status on racial differences in ovarian cancer treatment in a popluation-based analysis in Chicago. Joslin, Charlotte E., et al., et al. 2014, Gynecologic Oncology, pp. 285-291.

19. Cancer disparities in Rural Appalachia: Incidence, Early Detection, and Survivorship. Yao, Nengliang, et al., et al. 2016, The Journal of Rural Health, pp. 1-8.

20. Preoperative differentiation of malignant from benign ovarian tumors: the efficacy of morphology indexing and Doppler flow sonography. Ueland, FR, et al., et al. Oct 2003 , Gynecologic Oncology, pp. 46-50.

21. Ovarian cancer prediction in adnexal masses using ultrasound-based logistic regression models: a temporal and external validation study by the IOTA group. Timmerman, D, et al., et al. Aug 2010, Ultrasound in Obstetrics and Gynecology, pp. 226-34.

22. Frequency and disposition of ovarian abnormalities followed with serial transvaginal ultrasonography. Pavlik, EJ, et al., et al. Aug 2013, Obstetrics and Gynecology, pp. 210-7.

23. Serial ultrasonographic evaluation of ovarian abnormalities with a morphology index. Elder, JW, et al., et al. Oct 2014, Gynecologic Oncology, pp. 8-12.

24. Effectiveness of a multivariate index assay in the preoperative assessment of ovarian tumors. Ueland, FR, et al., et al. Jun 2011, Obstetrics and Gynecology, pp. 1289-97.

25. Evaluation of the diagnostic accuracy of the risk of ovarian malignancy algorithm in women with a pelvic mass. Moore, RG, et al., et al. Aug 2011, Obstetrics and Gynecology, pp. 280-8.

26. Ovarian malignancy risk stratification of the adnexal mass using a multivariate index assay. Bristow, RE, et al., et al. Feb 2013 , Gynecologic Oncology, pp. 252-9.

27. Validation of a second-generation multivariate index assay for malignancy risk of adnexal masses. Coleman, RL, et al., et al. Jul 2016, American Journal of Obstetrics and Gynecology, pp. e1-82. 
28. Clinical performance of a multivariate index assay for detecting early-stage ovarian cancer.

Longoria, TC, et al., et al. Jan 2014, American Journal of Obstetrics and Gynecology, pp. e1-9.

29. The effect of ovarian imaging on the clinical interpretation of a multivariate index assay.

Goodrich, ST, et al., et al. Jul 2014, American Journal of Obstetrics and Gynecology, pp. e1-65.

30. Cancer Statistics, 2016. Siegel, Rebecca L., Miller, Kimberly D., Jemal, Ahmedin. 2016, CA Cancer J Clin, pp. 7-30.

31. Disparities in Ovarian Cancer Care Quality and Survival According to Race and

Socioeconomic Status. Robert E. Bristow, Matthew A. Powell, Noor Al-Hammadi, Ling Chen, Phillip Miller, Phillip Y. Roland, David G. Mutch, William A. Cliby. 2013, Oxfort University Press, pp. 823-832.

32. Adherence to Treatment Guidelines for Ovarian Cancer as a Measure of Quality Care. Bristow, Robert E., Chang, Jenny, Ziogas, Argyrios, Anton-Culver, Hoda. 2013, Obstetrics and Gynecology, pp. 1226-1234.

33. Socioeconomic status as a predictor of adherence to treatment guidelines for early-stage ovarian cancer. Hodeib, Melissa, Chang, Jenny, Liu, Fong, Ziogas, Argyrios, Dilley, Sarah, Randall, Leslie M., Anton-Culver, Hoda, Bristow, Robert E. 2015, Gynecologic Oncology, pp. 121-127.

34. Spatial analysis of adherence to treatment guidelines for advanced-stage ovarian cancer and the impact of race and socioeconomic status. Bristow, Robert E., Chang, Jenny, Ziogas, Argyrios, Anton-Culver, Hoda, Vieira, Veronica. 2014, Gynecologic Oncology, pp. 60-67.

35. Impact of National Cancer Institute Comprehensive Cancer Centers on Ovarian Cancer Treatment and Survival. Bristow, Robert E., Chang, Jenny, Ziogas, Argyrios, Campos, Belinda, Chagex, Leo, Anton-Culger, Hoda. 2015, J Am Coll Surg, pp. 940950 .

36. Clinica, Sociodemographic, and Service Provider Determinants of Guideline Concordant Colorectal Cancer Care for Appalachian Residents. Fleming, Steven T, Mackley, Heath B., Camacho, Fabian, Seiber, Eric E., Gusani, Miraj J., Matthews, Stephen A., Liao, Jason, Yant, Tse-Chuan, Hwang, Wenke, Yao, Nengliang. 2013, The Journal of Rural Health, pp. 27-39.

37. Sociodemographic Disparities in Advanced Ovarian Cancer Survival and Adherence to Treatment Guidelines. Robert E. Bristow, Jenny Chang, Argryios Ziogas, Belinda Campos, Leo R. Chavez, Hoda Anton-Culver. 2015, Obstetrics and Gynecology, pp. 833-842.

38. Ovarian Cancer: Patterns of surgical care across the United States. Barbara A. Goff, Barbara J. Matthews, Michelle Wynn, Howard G. Muntz, Denise M. Lishner, Laura-Mae Baldwin. 2006, Gynecologic Oncology, pp. 383-390. 
39. The effect of neighborhood-level socioeconomic status on racial differences in ovarian cancer treatment in a popluation-based analysis in Chicago. Charlotte E. Joslin, Katherine C. Brewer, Faith G. Davis, Kent Hoskins, Caryn E. Peterson, Heather A. Pauls. 2014, Gynecologic Oncology, pp. 285-291.

40. Cancer disparities in Rural Appalachia: Incidence, Early Detection, and Survivorship.

Nengliang Yao, Hector E. Alcala, Roger Anderson, Rajesh Balkrishnan. 2016, The Journal of Rural Health, pp. 1-8.

41. Reasons for failure to deliver National Comprehensive Cancer Network (NCCN) - adherent care in the treatment of epithelial ovarian cancer at an NCCN cancer center. Erickson, Britt K., Martin, Jovana Y., Shah, Monjri M., Straughn, Michael, Leath, Charles A. 2014, Gynecologic Oncology, pp. 142-146.

42. Effect of surgeon specialty on processes of care and outcomes for ovarian cancer patients.

Earle, CC1, et al., et al. Feb 2006 , Journal of the National Cancer Institute, pp. 172-80.

43. Ovarian cancer prediction in adnexal masses using ultrasound-based logistic regression models: a temporal and external validation study by the IOTA group. Timmerman, D1, et al., et al. Aug 2010 , Ultrasound in Obstetrics and Gynecology, pp. 226-34. 


\section{NAME}

Robert Martin Ore

\section{EDUCATION}

Bachelor of Science, United States Naval Academy, Annapolis MD, May 1998

Doctor of Medicine, Marshall University School of Medicine, Huntington, WV, May 2008

\section{PROFESSIONAL POSITIONS HELD}

Communications Officer, USS Florida (Blue) SSBN-728, Bangor WA, Feb 2000 - Oct 2003

Resident, OB/GYN, Wilford Hall Medical Center, San Antonio TX, July 2008- June 2012 Attending OB/GYN, David Grant Medical Center, Travis AFB CA, July 2012 - June 2014 Fellow in GYN Oncology, University of Kentucky, Lexington KY, July 2014 - June 2017 Attending GYN/Oncologist, Wright Patterson AFB, Dayton OH, July 2017 - Present

\section{PROFESSIONAL HONORS}

None

\section{PROFESSIONAL PUBLICATIONS}

Population-Based Analysis of Patient Age and Other Disparities in the Treatment of Ovarian Cancer in Central Appalachia and Kentucky. Ore RM, Chen Q, DeSimone CP, Miller RW, Baldwin LA, van Nagell JR Jr, Huang B, Tucker TC, Johnson MS, Fredericks TI, Ueland FR. South Med J. 2018 Jun;111(6):333-341

Ovarian Cancer Incidence Corrected for Oophorectomy. Baldwin LA, Chen Q, Tucker TC, White CG, Ore RM, Huang B. Diagnostics (Basel). 2017 Apr 1;7(2). pii: E19. doi: 10.3390/diagnostics7020019.

Symptoms Relevant to Surveillance for Ovarian Cancer. Ore RM, Baldwin L, Woolum D, Elliott E, Wijers C, Chen CY, Miller RW, DeSimone CP, Ueland FR, Kryscio RJ, Nagell JR, Pavlik EJ.

Diagnostics (Basel). 2017 Mar 20;7(1). pii: E18. doi: 10.3390/diagnostics7010018.

First year participation in the affordable care act: costs and accessibility to gynecologic oncology. Pavlik EJ, Ore R, Toyama A, Woolum D, Pavlik TE, Baldwin L. Womens Health (Lond). 2015 Nov;11(6):865-82. doi: 10.2217/whe.15.79. Epub 2015 Sep 21.

Uterine arteriovenous malformation, images, and management. Ore RM, Lynch D, Rumsey C. Mil Med. 2015 Jan;180(1):e177-80. doi: 10.7205/MILMED-D-14-00145.

Malignant pericardial effusion and pericardial tumor involvement secondary to cervical cancer. Ore RM, Reed BG, Leath CA 3rd. Mil Med. 2013 Jan;178(1):e130-2. doi: 10.7205/MILMED-D-12-00314. 